\title{
Application of Walking Class in Practice Teaching of Architectural Engineering Technology Specialty
}

\author{
Wei Wang \\ Yunnan Urban Construction Vocational College, Kungming, Yunnan, China, 651700
}

Keywords: walking class; architectural engineering technology specialty; practice

\begin{abstract}
In view of the problems existing in the practice teaching of architectural engineering technology, this paper discusses the general rules of "walking class" in practice teaching in the theory course of architectural engineering technology. Through the fully integration of the theoretical and practice education, and the focus of the team building, the cooperation between teachers and students to achieve the purpose of practical teaching of building engineering technology is emphasized. In the course of teaching implementation, it is necessary to highlight the integrity and systematicness of the "walking class" teaching system, and the ideological guidance of the teaching process, to fully mobilize the autonomy and initiative of students.
\end{abstract}

\section{Introduction}

In the context of quality education, the importance of practical teaching is self-evident and the key to cultivating innovative talents in architectural engineering technology [1]. In the teaching of architectural engineering technology, the traditional "theory of indoctrinization" teaching model has been unable to meet the objective requirements of the development of the times. Teachers must comprehensively and objectively analyze factors influencing various aspects, optimize and improve classroom teaching methods, and establish scientific and rational practical teaching systems to ensure the smooth realization of the professional training objectives of the new era and cultivate a large number of high-quality applied talents required by the social market. The walking class is closely linked with the real knowledge class. All topics are related to the architectural engineering technology specialty, and the students' perspectives and advantages are well received by the students.

\section{Problems in Practice Teaching of Building Engineering Technology Specialty}

\subsection{Lack of perfect practice teaching system}

In the course of practice teaching of architectural engineering and technology, some colleges and universities do not keep pace with the times, understand the concept of vocational education and the training goal of professional talents, which lead to the unscientific and unreasonable practice teaching system, the unreasonable arrangement of the practical teaching content and the less teaching time in the practice course. It is not conducive to the smooth realization of the goal of practice teaching. In the classroom teaching, teachers still use the theory of indoctrinization teaching model, pay too much attention to the teaching of professional theory, and instill a large number of curriculum knowledge to the students at one time. The interaction between students and teachers is very few, the atmosphere of the class is dull and the efficiency of the classroom teaching is low, which is not conducive to the long-term development of vocational education. And it affects the improvement of students' comprehensive practical ability.

\subsection{The insufficient construction of training base}

In the practical teaching of architectural engineering technology, some schools do not realize the importance of practical teaching. The training base that has been constructed is in a form, and the professional practice teaching efficiency is very low. Some school does not increase the investment in 
the practical teaching technology and equipment, which lead to the imperfect situation of the training equipment and facilities, and thus cannot effectively meet the objective requirements of the professional students in the practice teaching [2]. Besides, the low utilization rate of intelligent equipment and facilities of the training base, and insufficient attention to the maintenance of the practical facilities, have led to problems as shortens the service life of the facilities, which is not conducive to the improvement of practice teaching quality.

\section{The Importance of Walking Classroom in Practical Teaching of Architectural Engineering Technology Specialty}

\subsection{The practical and applicable requirement of the profession}

In terms of architectural engineering technology, it has strong application and practicality. In the entire teaching system, the practical teaching system occupies the core position. According to the relevant investigation and analysis, most of the students majoring in construction engineering and technology are engaged in construction site construction technology and supervision work after graduation. There are not many students engaged in construction administrative management, architectural design, etc. Some students do not engage in professional-related work, which means that most of the students in the profession after graduation still work in the front line. In view of this situation, in the teaching process of architectural engineering technology, teachers should use this as a basic point, build a reasonable practical teaching system, carry out a series of practical teaching activities, and realize the importance of practical teaching. And cultivate large number of high-quality senior engineering professionals to the social market to effectively fill social vacancies, and this professional student will be better able to perform his or her job after graduating and fully demonstrate his own values, which urges the students to better perform their duties and fully display their own values after graduation.

\subsection{The best presentation of teaching team to organize teaching}

Teamwork is the basic strategy for dealing with complex and varied construction projects [3]. Walking class to give full play to the team's strength, to change the previous practice teacher teaching "individual combat" situation, integrate the teaching team, the implementation of "team research." In particular, first of all, teachers participating in the teaching have a scientific division of labor, sincere cooperation, and seamless integration. This is the basis for organizing and practicing activities, which is beneficial to the mutual complementarity between teachers and the overall strength of the teaching team. Second, the students form a project team, decomposite tasks, division of labor and collaboration, while fully mobilizing the enthusiasm of students to explore real knowledge, promote students to actively participate in the practice, build a cooperative learning model of cooperation; Finally, teachers and classmates work together to enhance the effectiveness of teaching in collaboration. In the collaboration, teachers feel the passion and vitality of students, understand the students' ideological conditions, and lay a solid foundation for teaching; students participate in the teaching process, give full play to their subjective initiative, and increase their participation in the teaching process, making practice teaching possible, and the activity became the process of the participants' self-building.

\section{Construction Approach of Practical Teaching System for Architectural Engineering Technology Specialty}

\subsection{Focus on the integrity and systematicness of the teaching system}

As a practice teaching system composed of a series of "walking", walking classroom is not a random combination of scattered practice teaching activities, but a complete practical curriculum system with definite teaching themes, teaching content system, teaching space continuity, teaching evaluation and so on. The specific performance in the following aspects. First, the teaching system is 
complete. The perfect theory course practice teaching is a complete teaching system which is formed by a series of teaching themes, together with each other under the unified teaching theme. To make the whole "walking classroom" form a teaching system with distinctive features, which not only pays attention to the development of the society but also takes care of the students' own growth, not only goes into the historical experience but also returns to the reality of life, not only pays attention to the hot spot but also the difficulties in the real work. Second, the teaching content is pragmatic. In order to give full play to the role of theory in connection with practice, practical teaching of theoretical courses must be scientific and practical. The selection of teaching content in the walking class focuses on two points: pertinence and inspiration. Pertinence, mainly refers to the design of teaching content aiming at students' reality, stimulating students' interest in learning, and encouraging students to take the initiative to practice. Enlightening, mainly refers to the design of teaching content in a series of topics surrounding the theme, the design of science, interrelated chain of problems as guidance, from the problem caused by students thinking, traction teaching content to promote the students to think problems, answer questions to expand the theoretical field of vision, and improve the spiritual realm. Third, the teaching space is continuous. The continuity of space selection in practice teaching will enable students to understand theoretical knowledge more and more deeply in more and more familiar teaching scenarios. The continuous undertaking of the teaching space makes the series of "walking" integrated. Students study in a continuous cultural atmosphere and continuous time and space to improve the actual effect of practical teaching. Fourth, the teaching evaluation is unified. The integrity of the practical teaching system determines the unity of the evaluation system. Relying on multiple theoretical courses and "walking classes" that are spread over four semesters, they follow a unified evaluation method and evaluation criteria. This not only facilitates the deepening of students' understanding of relevant theories, but also transforms the evaluation results into the basis for improving the quality of the next "walking".

\subsection{Focus on the ideological and orientation of teaching}

First, emphasize the ideological and guiding nature of teachers' on-site teaching. "Walking Classroom" is an extension of traditional classroom teaching. Teachers' on-site teaching is the most crucial point. It is the finishing touch for "walking” activities. If the ideological and orientation of this point is weakened, practical teaching will inevitably flow into the form. Even existed in name only. In addition, the students come to the changing teaching scene, the strangeness and curiosity of the teaching environment could easily lead to a vague understanding of the purpose of teaching, and a deviation from the understanding of the teaching content. Therefore, teachers must strengthen the ideology and orientation of the "walking class" through on-the-spot instruction, and through analysis of the sentiments, and proper explanation. Second, emphasize the ideological nature of the summary of activities. The summary link is a key link in improving the ideology of practical teaching. This link should be completed by teachers and students. It can not only be reflected as a simple answer by the trainee to the teacher, but also a general summary of the teacher's practical activities. It should also be reflected in the sincerity of the trainee's heartfelt readme through the "walking”. Therefore, before summing up, we should inspire students to think carefully about the following points: What is the deepest thing about this "walking”? Is there incomprehensible thinking and real doubt? What aspects of previous understanding have been corrected, what aspects have been improved, and what aspects have been deepened? Through such a summary, the content of theoretical teaching is deepened in the minds of students, sublimated in knowledge, validated in practice, and transformed in action.

\subsection{Focus on the autonomy and initiative of students}

Educational activities are the unification of the process of "shaping" and "self shaping" [4]. No effective education can be achieved without the participation of students, and their self shaping. Practice teaching activities in theory class emphasize the role of practice in education. Under the guidance of teachers, practical teaching is an objective activity that students can actively transform the objective material world. Among them, mobilizing the initiative of students and enabling them to participate in teaching activities actively is the core purpose of practical teaching activities. In the 
actual operation of "walking class", we mainly promote students' autonomy and initiative from the following aspects: First, emphasize the participation of students in the design of teaching. In the instructional design process, from the setting of the theme to the design of the practice, participants are involved in the design, so that the theme of practice is closer to the reality of the students, and the theme of practice is more practical, so that trainees have a good ability to control practical activities. This control ability provides the driving force for the following practical activities to continue to explore and strive to complete. Second, emphasize that students lead the teaching display. In practice teaching, the teaching display is completely led by the trainees. According to their specialty, the teaching content is displayed in different ways so that the teaching process is free from the situation of the teacher. The students fully take the initiative in the classroom and devote themselves to their favorite teaching process, which is undoubtedly an important part of improving the quality of practical teaching. Third, emphasize the participants' independent participation in teaching evaluation. The scientific nature of the teaching evaluation mechanism is an important indicator for measuring practical teaching. The "walking class" adopts a mechanism for participants to participate in the teaching process evaluation. Each student participating in the teaching is a designer and implementer of practical activities. They have a considerable degree of persuasiveness in evaluating their own and their peers' participation in the practice activities. The mechanism of students' evaluation is taken randomly, so that each student and his fellow students may become the evaluators of the practical activities, and make them more actively put into the activities of each link, think carefully about the subject of the course, take the initiative to participate in the practice process, and objectively evaluate the effect of the activities. At the same time, the individual students' evaluation of the activities directly affects the evaluation of the follow-up practice, making the evaluators think more carefully and conscientiously. This evaluation mechanism could help students enhance their participation in the teaching process unconsciously.

\section{Summary}

In the teaching of architectural engineering technology, teachers must keep pace with the times and establish a new education concept. In the teaching of architectural engineering and technology, teachers must keep pace with the times, set up a new educational concept, realize the importance of practical teaching, take the social market as the guidance, analyze the relevant duties, tasks and work process objectively, and build a rational practice teaching system to promote the organic integration of theory and practice teaching, providing more opportunities for students to participate in practice. Through the use of walking class, the learned knowledge is flexibly applied to practice, and students comprehensive skills are improved so that they can go to work after graduation and fully display their own values.

\section{Acknowledgement}

Application of walking classroom in Architectural Engineering Technology Specialty Project number: 2016ZZX337

\section{References}

[1] Qiu Lihui, Wang Yaowu. Research on the Reform of Practical Teaching System of Building Engineering Technology Specialty Based on the Construction of Characteristic Specialty[J]. Journal of Hubei Correspondence University, 2016 (10), P55.

[2] Zhang Yunping. Construction and Implementation of Practical Teaching System for Architectural Engineering Technology Major[J]. Education and teaching forum, 2013 (2).

[3] Fu Liwen, Nie Liwu. Practice and Teaching System of Building Engineering Technology Specialty[J]. Heilongjiang Science and Technology Information, 2015 (28), p91. 
[4] Wang Qiang, Yu Hui. Exploring the Training Objectives of Practice Teaching in Architectural Engineering Technology[J]. Talents, 2013(25), p39. 